\section{The New Einstein Theory and the Equations of Motion}

THE new Einstein' theory is mathematically attractive; but its role in science can only be established through the conclusions that can be drawn from it. Einstein himself hopes that his new theory will turn out to be a real field theory, that is, he believes that his equations possess solutions free from singularities and representing particles. To show that such solutions exist (or that they do not) is a difficult task. But we can ask a simpler question : Does the new Einstein theory give equations of motion which are consistent with experience? That is, do we obtain, in the first approximation, the Lorentz equations of motion ?

In a series of papers ${ }^{2}$, the problem of motion, as determined by the field equations alone, was investigated according to general relativity theory. The same method in principle, though with some appropriate changes, can be applied to Einstein's new theory. Unfortunately, the equations of motion remain Newtonian and are uninfluenced by the electromagnetic field.

Yet it is possible that this negative result is no fault of Einstein's theory, but of the conventional interpretation by which it was derived. Indeed, the derivation is based on the assumption that far from the 'centre' of a particle the symmetric part of the metric tensor characterizes the gravitational field, and the antisymmetric part the electromagnetic field.

Universities of Toronto and Warsaw. LEOPOLD INF'ELD

$$
\text { Sept. } 15 .
$$

1 Finstein, A., "The Meaning of Relativity", 133-147 (Princeton University Press, 1950)

${ }^{2}$ Finstein, A., Infeld, I., and Hoffmann, B., Ann. Math., 89 (1) 66 (1938). Einstein, A., and Infeld, L., Ann. Math., 41 (2), 797 (1940); Can. J. Math., 1, (3), 209 (1949). Infeld, L., Phys. Rev, $797(1940)$.

\section{Reduction of some Cyclic Amides by Lithium Aluminium Hydride}

ON reduction by lithium aluminium hydride, amides usually give amines ${ }^{1}$ it has now been found that $\mathrm{N}$-methyl phenanthridones behave rather differently, yielding quaternary (phenanthridinium) compounds. Phenanthridones are reduced to phenanthridines. Thus, N-methyl phenanthridone and N-3-dimethyl phenanthridone (m.p. $139^{\circ}$; found: $\mathrm{C}, 80 \cdot 6 ; \mathrm{H}, 5.8 ; \mathrm{N}, 6 \cdot 15$ per cent; calc. for $\mathrm{C}_{15} \mathrm{H}_{18} \mathrm{ON}: \mathrm{C}, 80.7 ; \mathrm{H}, 5.8 ; \mathrm{N}, 6.3$ per cent) reduced in ethereal solution on the $300-\mathrm{mgm}$. scale gave respectively 60 and 55 per cent yields of the quaternary iodides (3-methyl phenanthridine methiodide, m.p. $278^{\circ}$; found : C, 53.8; H, 4.1; N, 4.5 ; I, 37.4 per cent; calc. for $\mathrm{C}_{13} \mathrm{H}_{14} \mathrm{NI}$ : C, 53.75; $\mathrm{H}, 4 \cdot 2 ; \mathrm{N}, 4 \cdot 18 ; \mathrm{I}, 37 \cdot 9$ per cent). The analogous $\mathrm{N}$-methyl quinolone likewise geve $\mathrm{N}$-methyl quinolinium chloride (identified as its platinichloride), but the reaction was less easy, two hours refluxing in dibutyl ether giving a 20 per cent yield. Among the reduction products of $\mathrm{N}$-methyl pyridone, only a trace of quaternary compound (isolated as picrate) was found, together with methylamine ( 7 per cent isolated as the platinichloride).

Phenanthridone and 1-methyl phenanthridone (m.p. $240^{\circ}$; found: C, $80.0 ; \mathrm{H}, 5 \cdot 3$ per cent; calc. for $\mathrm{C}_{14} \mathrm{H}_{11} \mathrm{ON}$ : $\mathrm{C}, 80.4 ; \mathrm{H}, 5.3$ per cent) reduced on the $100-\mathrm{mgm}$. scale gave respectively 70 and more than 50 per cent yields of the corresponding phenanthridines : no precautions were taken to prevent air-oxidation of any dihydro derivative which was formed ${ }^{2}$ 2-Hydroxy quinoline reduced $(6 \mathrm{hr}$.) in boiling dibutyl ether gave quinoline (26 per cent as the picrate) and, isolated chromatographically, tetrahydroquinoline (5 per cent as the benzoyl derivative) ; 2 -hydroxy pyridine similarly gave pyridin $\theta$ (8 per cent as the picrate) and piperidine ( 1.5 per cent as the $p$-toluenesulphonyl derivative). Pyridine refluxed in dibutyl ether with lithium aluminium hydride for $3 \mathrm{hr}$. gave a 10 per cent yield of piperidine (isolated as the $p$-toluenesulphonyl derivative), no unchanged pyridine being recover $€$ d.

P. DE MAYO

W. RIGBY

Department of Chemistry,

Birkbeck College,

London, E.C.4. July 27.

${ }^{1}$ Nystrom and Brown, J. Amer. Chem. Soc., 70, 3738 (1948). Julian and Printy, $J$. Amer. Chem. Soc., 71,'3206 (1949). Uffer and Schlittler, Helv. Chim. Acta, 31, 1397, 1948).

2 Wooten and McKee, J. Amer. Chem. Soc., 71, 2946 (1949).

\section{bis-peri-Phenylenenaphthalene}

bis-peri-Phenylenenaphthalene (I) has been synthesized, and the preparation will be described (by H. W. D. S. and S. H. T.) in a forthcoming communication.

We describe herein the ultra-violet absorption spectrum of this hydrocarbon. In the accompanying graph its spectrum is superimposed on that of fluoranthene. The $p$-bands ${ }^{1}$ are clearly separated from $\beta$-bands ${ }^{1}$, but the general similarity of the curves is so great that one may say that: (i) the

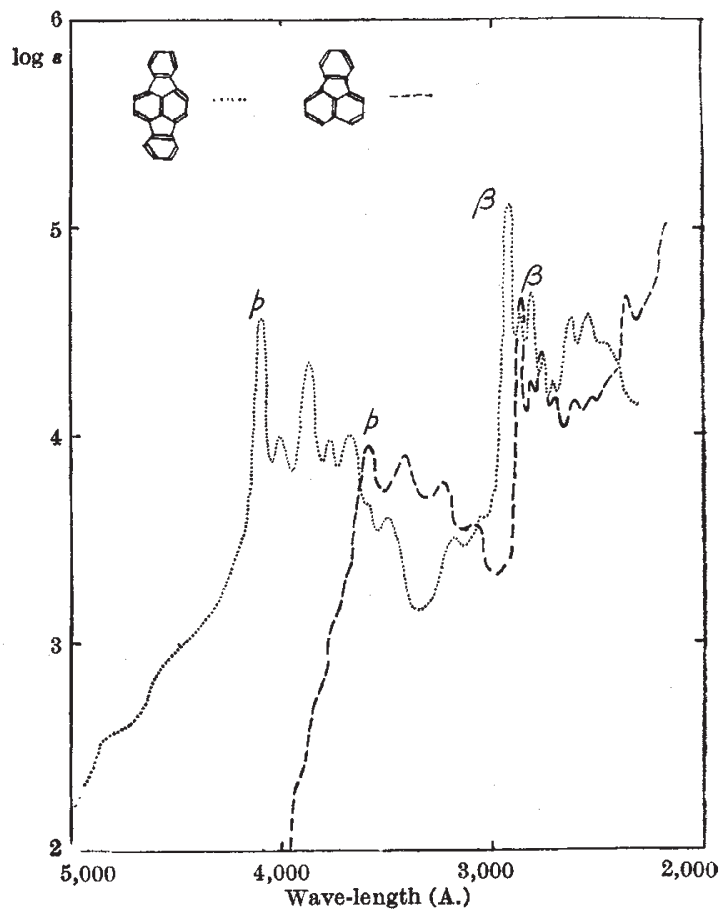

Absorption spectra of bis-peri-phenylenenaphthalene $(. .$.$) and$ of fluoranthene (- - - ) in ethanol. Band maxima (in A.) bis-peri-phenylenenaphthalene : $p$-bands $4100,4020,3870,3795$, 3670,3490 . $\beta$-bands $2925,2865,2810,2760,2705$. $\beta$-bands 2025 530. Fluoranthene : $p$-bands $3585,3420,3230, \beta^{\prime}$-bands 2360 